\title{
Selenium in Diketopyrrolopyrrole-based Polymers: Influence on Electronic Properties and Charge Carrier Mobilities
}

\author{
Joydeep Dhar ${ }^{[\mathrm{a}]}$ Catherine Kanimozhi, ${ }^{[\mathrm{a}]}$ Nir Yaccobi-Gross, ${ }^{[\mathrm{b}]}$ Thomas D. Anthopoulos, ${ }^{[\mathrm{b}]}$ Ulrike Salzner, ${ }^{[\mathrm{c}]}$ \\ and Satish Patil*a]
}

Dedicated to the memory of outstanding chemist Prof. Michael Bendikov

\begin{abstract}
Diketopyrrolopyrrole (DPP)-based $\pi$-conjugated copolymers with thiophene have exceptionally high electron mobilities. This paper investigates electronic properties and charge carrier mobilities of selenophene containing analogues. Two new copolymers, with alternating thiophene DPP (TDPP) and selenophene DPP (SeDPP) units, were synthesized. Two side-chains, hexyl (Hex) and triethylene glycol (TEG) were employed, yielding polymers designated as PTDPPSeDPP-Hex and PTDPPSeDPP-TEG. Selenophene systems have smaller band gaps, with concomitant enhancement of the stability of the reduced state. For both polymers, ambipolar mobilities were observed in organic field-
\end{abstract}

effect transistors (OFET). Grazing incidence X-ray diffraction (GIXD) data indicates preferential edge-on orientation of PTDPPSeDPP-TEG, which leads to superior charge transport properties of the TEG substituted polymer, as compared to its Hex analogue. Time-dependent-density functional theory (TDDFT) calculations corroborate the decrease in the optical band gap with the inclusion of selenophene. Ambipolar charge transport is rationalized by exceptionally wide conduction bands. $\triangle S C F$ calculations confirm the larger electron affinity, and therefore the greater stability, of the reduced form of the selenophene-containing DPP polymer in presence of chloroform.

Keywords: band gap · charge carrier injection - copolymerization - diketopyrrolopyrrole · selenophene

\section{Introduction}

Structure-property relationships of conjugated polymers have been investigated intensely for decades, aiming at a comprehensive understanding of charge carrier generation and transport. ${ }^{[1]}$ The donor-acceptor (D-A) concept was introduced to decrease band gaps and to increase band width of the $\pi$-conjugated polymers. ${ }^{[2]}$ As expected, band gaps of D-A systems can be tuned over a wide range, and small band gap D-A polymers are employed to harvest the major part of the solar spectrum. ${ }^{[3]}$ Recently, tandem organic solar cell devices containing difluorobenzothiadiazole have touched a new horizon by reaching power conversion efficiencies (PCEs) of over $10 \%{ }^{[4]}$ In most cases, however, using strong acceptors leads to extremely narrow conduction bands ${ }^{[5]}$ and low electron mobility. ${ }^{[6]}$ As a result, air-stable molecular $\pi$-systems with higher electron mobility than their corresponding polymers have been reported, ${ }^{[7]}$ but air-stable n-type polymers with balanced hole and electron mobilities are rare exceptions. ${ }^{[8]}$ Intramolecular charge transfer in D-A copolymers leads to large polarizabilities and efficient $\pi-\pi$ stacking, ${ }^{[9]}$ imparting long-range order and improving charge carrier mobilities in organic field-effect transistors (OFETs). ${ }^{[8 a, 10]}$ Lee and Kang reported diketopyrrolopyrrole (DPP)-based polymeric semiconductors with hole mobilities of up to $12 \mathrm{~cm}^{2} \mathrm{~V}^{-1} \mathrm{~s}^{-1}$. ${ }^{[1]}$ Our group has used side chain engineering to design copolymers of thiophene and DPP (TDPP) with electron mobilities of $3 \mathrm{~cm}^{2} \mathrm{~V}^{-1} \mathrm{~s}^{-1}$. ${ }^{[12]}$ DPP-based D-A polymers are planar, and their properties can be tuned by modifying the donor and by introducing a variety of alkyl chains on the lactam

[a] J. Dhar, C. Kanimozhi, S. Patil

Solid State and Structural Chemistry Unit

Indian Institute of Science

Bangalore 560012 (India)

Tel: $(+91)$ 80-22932651

Fax: $(+91)$ 80-23601310

e-mail: satish@sscu.iisc.ernet.in

[b] N. Yaccobi-Gross, T. D. Anthopoulos

Department of Physics and Centre for Plastic Electronics

Blackett Laboratory

Imperial College London

London 7W72BW (UK)

[c] U. Salzner

Department of Chemistry

Bilkent University

06800 Bilkent, Ankara (Turkey)

Supporting information for this article is available on the WWWW under http://dx.doi.org/10.1002/ijch.201400051. 
ring. ${ }^{[13]}$ With thiophene and alternating triethylene glycol (TEG) and hexyl (Hex) side groups on the DPP units, ambipolar charge transport in OFETs was observed. ${ }^{[12]}$ However, there is still a need for improvement regarding the imbalance in electron and hole transport, as hole mobilities remain about twice as large as electron mobilities. Balanced charge transport, however, is essential for ambipolar transistors, complementary circuits, and organic photovoltaics. ${ }^{[8 \mathrm{~b}, 14]}$ The common strategy for improving the stability of the reduced form is to increase the electron affinity (EA) to around $4 \mathrm{eV}$ by rational molecular design, and to decrease the barrier for electron injection. ${ }^{[7]}$ This approach provides stability of the polymeric anion against oxidation by atmospheric oxygen and moisture.

Theoretical calculations have shown that DPP polymers are a new family of D-A polymers with broad valence and conduction bands. ${ }^{[15]}$ The lowest unoccupied molecular orbital (LUMO) in such DPP-based materials is delocalized over the lactam ring, as well as on the donor group, predicting improved n-type character of such D-A copolymers. ${ }^{[12,13,16]}$ Since there is electron density on the chalcogen atom in the LUMO, but not in the highest occupied molecular orbital (HOMO), changing the chalcogen atom allows manipulation of the LUMO relative to the HOMO energy. ${ }^{[17]}$ As we move down the periodic table, the ionization potentials of chalcogen atoms gradually decrease, and many research groups ${ }^{[14 a, 18]}$ have confirmed the prediction ${ }^{[19]}$ that replacing sulfur with selenium or tellurium lowers the LUMO energy. For various polymeric semiconductors, integration of selenium in the polymer repeat unit has led to a reduction of the band gap, and an increase in charge carrier mobility, compared to sulfur analogues. ${ }^{[16,20]}$ The better charge transport in selenophene derivatives has been attributed to stronger Se...Se interactions, leading to efficient intraand intermolecular charge transfer properties. ${ }^{[21]}$ None- theless, comprehensive understanding of the role of selenium in D-A polymers is lacking. ${ }^{[13,14,16,18 b, 20 b, 22]}$. Here we present the synthesis of two new D-A polymers with alternating TDPP and selenophene DPP (SeDPP) units. The two polymers are designated as PTDPPSeDPP-Hex and PTDPPSeDPP-TEG, depending on the side-groups. The influence of selenophene on photophysical and electrochemical properties has been investigated by cyclic voltammetry, absorption spectroscopy, and time-dependent density functional theory (TDDFT). In particular, we discuss the impact of solid-state packing on charge transport properties by means of grazing incidence X-ray diffraction (GIXD) study.

\section{Results and Discussion}

\subsection{Synthesis and Characterization}

The synthetic routes for the monomers and copolymers are outlined in Schemes 1 and 2, respectively. TDPP and SeDPP monomers were synthesized by procedures reported in the literature. ${ }^{[23]} \mathrm{N}$-alkylation, followed by esterification or bromination at 5 and $5^{\prime}$ position of thiophene or selenophene ring, was carried out to prepare the monomers, M1-M3. The branched alkyl chain, octyldodecyl, was introduced at the lactam unit of TDPP, whereas SeDPP was functionalized with linear Hex and TEG chains. Polymerization was carried out by Suzuki cross-coupling between the boronic ester of TDPP (M1) and the dibromo derivative of SeDPP (M2 or M3) at $110^{\circ} \mathrm{C}$ for 48 hours in dry toluene, as shown in Scheme 2. Variation of side chains resulted in different solubilities of the two polymers. The TEG substituted polymer was readily dissolved in chloroform, while the Hex substituted polymer was completely soluble in hot chlorobenzene. Absorption spectra of the two polymers were recorded in tetrahydrofuran (THF), chloroform, and $o$-dichloroben-

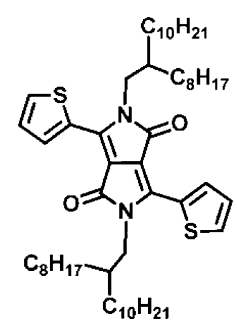

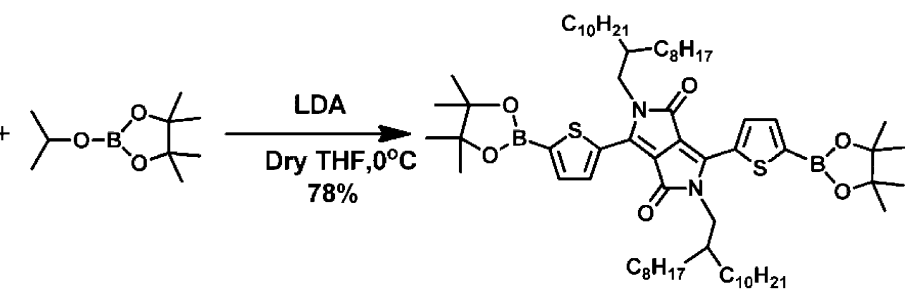<smiles></smiles>

$\mathrm{N}$ - bromosuccinimide

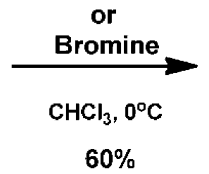

(TEG) (a)

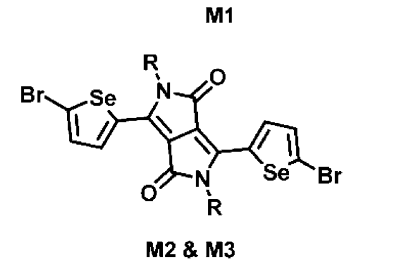

(Hex) (b)

Scheme 1. Synthetic pathway for the monomers M1-M3. 

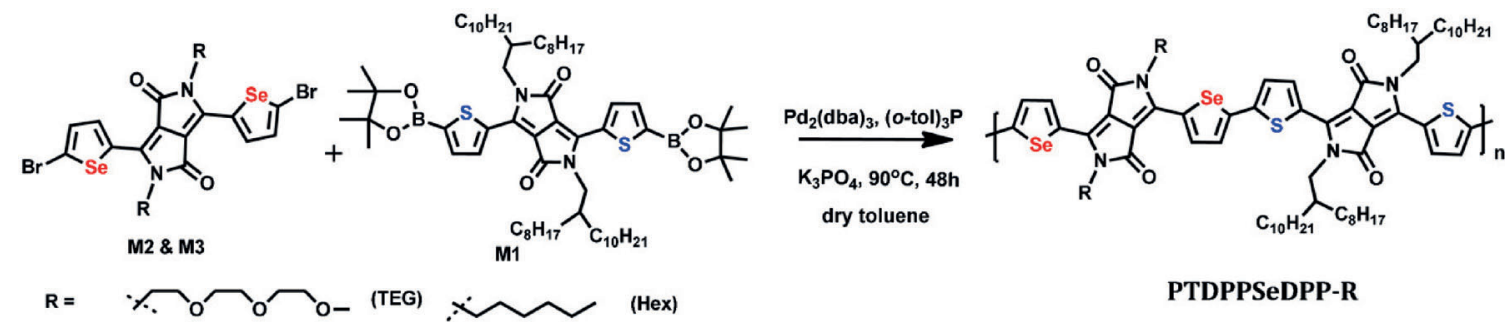

PTDPPSeDPP-R

Scheme 2. Synthesis of the copolymers PTDPPSeDP-Hex and PTDPPSeDPP-TEG.

zene (ODCB) at room temperature to assess solvent dependent aggregation of polymers (SI 6). It has been found that the Hex functionalized polymer, PTDPPSeDPP-Hex shows broader and blue shifted ( $40 \mathrm{~nm}$ ) absorption spectra in THF and $o$-dichlorobenzene, as compared to the spectrum recorded in chloroform. This indicates that PTDPPSeDPP-Hex tends to aggregate in THF and o-dichlorobenzene. On the contrary, PTDPPSeDPP-TEG exhibited almost similar absorption properties in all the three solvents. This suggests that the degree of aggregation of PTDPPSeDPP-TEG is independent of solvent, if aggregates really exist at all at room temperature. The molecular weights were determined by gel permeation chromatography (GPC) and the results are summarized in Table 1.

Table 1. Molecular weight distribution of the synthesized copolymers.

\begin{tabular}{llll}
\hline Polymer & \multicolumn{3}{l}{ Molecular Weight } \\
\cline { 2 - 4 } & $\begin{array}{l}\mathrm{M}_{\mathrm{n}} \\
\mathrm{kg} / \mathrm{mol}\end{array}$ & $\begin{array}{l}\mathrm{M}_{\mathrm{w}} \\
\mathrm{kg} / \mathrm{mol}\end{array}$ & PDI \\
\hline PTDPPSeDPP-Hex & 21.8 & 65.8 & 3.01 \\
PTDPPSeDPP-TEC & 12.1 & 34.0 & 2.79 \\
\hline
\end{tabular}

\subsection{Photophysical Properties}

Figure 1 shows absorption spectra of PTDPPSeDPP-Hex and PTDPPSeDPP-TEG in chloroform and in thin film. We observe a broad and intense absorption peak extending from $500 \mathrm{~nm}$ to $1200 \mathrm{~nm}$, and additional peaks between 300 and $480 \mathrm{~nm}$. The optical band gaps calculated from the solution state absorption spectra of these two polymers are $1.14 \mathrm{eV}$. In $\mathrm{CHCl}_{3}$ solution, PTDPPSeDPPHex has an absorption maximum $\left(\lambda_{\max }\right)$ at $825 \mathrm{~nm}$, with a shoulder at a longer wavelength. In thin film, $\lambda_{\max }$ is red-shifted to $850 \mathrm{~nm}$, and the intensity of the shoulder is enhanced. The PTDPPSeDPP-TEG copolymer shows a broad absorption with $\lambda_{\max }$ at $857 \mathrm{~nm}$ in solution, which is shifted bathochromically to $889 \mathrm{~nm}$, with concomitant appearance of a shoulder at a lower energy in thin film. Compared with the solution spectra, thin film absorption shows well-resolved, vibronic features, and broadening of the low-energy band, which is attributed to intermolecu-

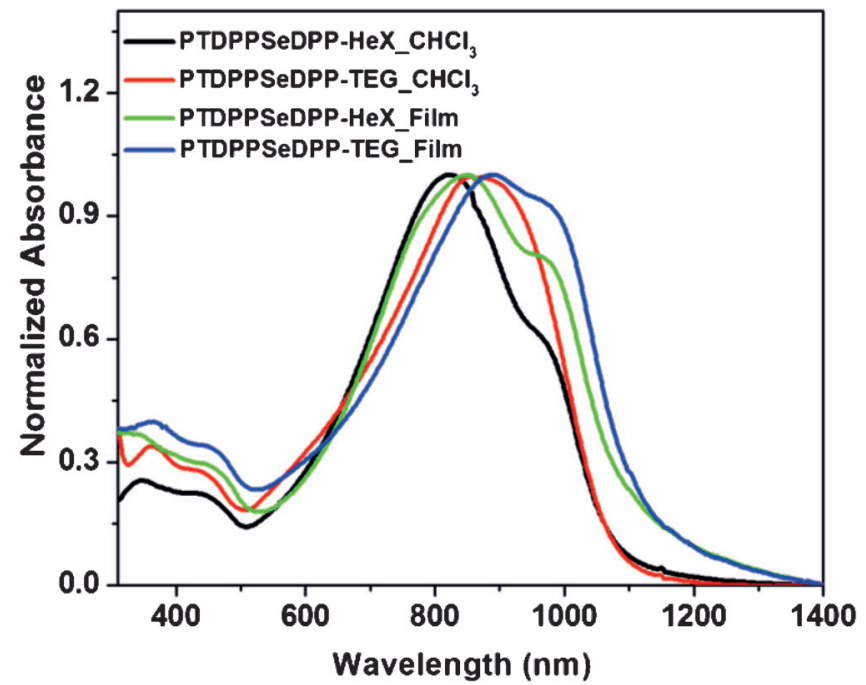

Figure 1. UV-visible absorption spectra of the copolymers in chloroform and thin film.

lar interactions and the aggregation of polymer chains in the thin film. The onset of absorption shift beyond $1300 \mathrm{~nm}$ indicates very small solid state optical band gaps for these polymers. The low-energy absorptions of selenophene-containing polymers are red-shifted and broadened, in comparison with their thiophene analogues. ${ }^{[12]}$ This was also observed previously in theoretical and experimental studies. ${ }^{[16,20 \mathrm{~b}]}$

\subsection{Theoretical Studies}

As observed previously, ${ }^{[24]}$ monomer spectra of TDPP and SeDPP (Figure 2a) show dual band absorption, with a strong feature at $520 \mathrm{~nm}$ and several weaker ones between 220 and $320 \mathrm{~nm}$. SeDPP absorbs at slightly lower energies than TDPP. There is no difference in absorbance in the gas phase between the methyl and TEG substituted oligomers. Upon increase in chain length (Figure 2b), all absorptions are red-shifted, but only the low energy peak increases in oscillator strength. The energy difference between TDPP and SeDPP absorptions increases for longer oligomers. Thus, $\pi$-conjugation is stronger with seleno- 

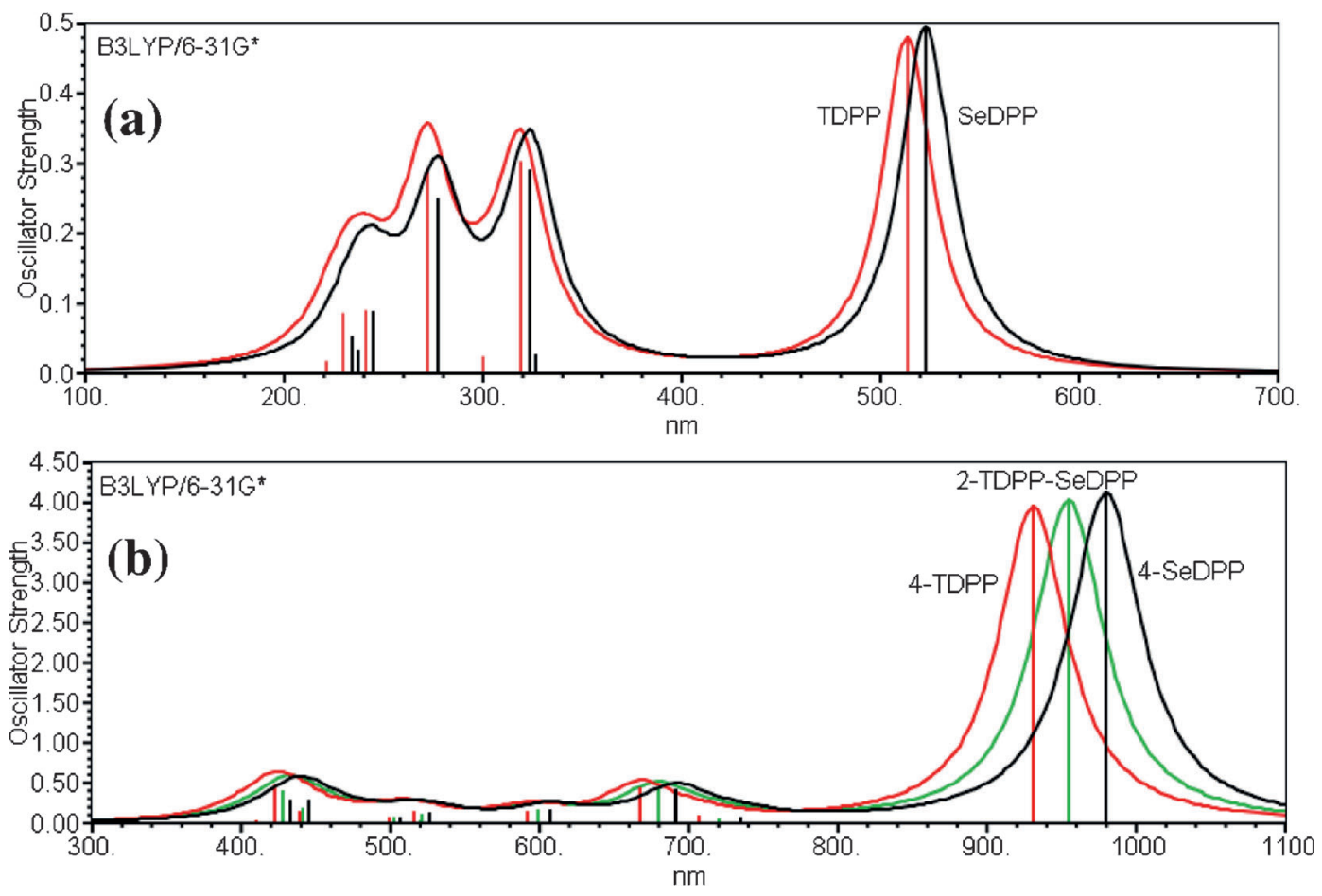

Figure 2. Calculated absorption spectra of TDPP and SeDPP monomers (a) and 4-TDPP, 4-SeDPP, and 2-TDDP-SeDPP (b).

phene than with thiophene. 2-TDPP-SeDPP absorbs intermediately, between 4-TDPP and 4-SeDPP.

The low-energy peak of 2-TDPP-SeDPP lies within the experimentally observed wide absorption band of the polymer. The vertical peak is actually closer to the shoulder in thin film than to $\lambda_{\max }$. There may be several reasons for this. In general, B3LYP underestimates excitation energies of conjugated systems. Hence, the experimental results for polymers are matched with shorter oligomers. At the same time, conjugation lengths of polymers are unknown, but are definitely not infinite. As changes in properties develop in a regular manner with increasing chain length without any discontinuities, 4TDDP, 4-SeDPP, and 2-TDDP-SeDDP can be used without any disadvantage, to analyze the properties of the polymers.

In the ground state of 4-TDPP, 4-SeDPP, and 2-TDDPSeDDP, DPP units act as acceptors, having charges of -0.15 e between thiophene rings and -0.16 e between selenophene rings. In the first excited state, the charges on DPP are reduced to -0.13 and -0.14 e, respectively. Thus, DPP loses electron density upon excitation. The low-energy absorption is therefore not a charge transfer band, and the little charge that is transferred, is from acceptor to donor. The very small charge transfer contribution to this excitation explains its large intensity and the strong red-shift of the band upon increasing the chain length.

Analysis of the electronic configurations contributing to the low-energy absorption in 2-TDPP-SeDPP identifies it as a HOMO-LUMO $\pi \rightarrow \pi^{*}$ transition. The higher energy features involve $\mathrm{HOMO}-1 \rightarrow \mathrm{LUMO}+1$, $\mathrm{HOMO}-2 \rightarrow$ LUMO, and $\mathrm{HOMO} \rightarrow \mathrm{LUMO}+2$ transitions. In this respect, DPP-DPP copolymers resemble homopolymers and differ from other D-A systems, e.g., benzothiadiazole polymers, where the high energy transitions are strong and consist of $\mathrm{HOMO} \rightarrow \mathrm{LUMO}+\mathrm{n}$ transitions, with $\mathrm{n}$ being the number of repeat units in the oligomer $(\mathrm{HOMO} \rightarrow \mathrm{LUMO}+4$ for tetramers $)$.

The large intensity of the $\pi \rightarrow \pi^{*}$ transition arises from the fact that HOMO and LUMO are completely delocalized (Figure 3). As a consequence, occupied and unoccupied orbitals have significant dispersion. Extrapolation of band edges reveals that the conduction band is wider than the valence band, which predicts high electron mobility in these systems.

$\triangle \mathrm{SCF}$ calculations for 4-TDDP in presence of a solvent predict the ionization potential (IP) and EA to be 5.00 and $3.57 \mathrm{eV}$. The corresponding values for 2-TDDPSeDPP are 4.98 and $3.60 \mathrm{eV}$. Thus, selenophene lowers the IP and increases the EA, relative to the thiophene analogue. The resulting transport gaps (IP-EA), are $1.43 \mathrm{eV}$ and $1.38 \mathrm{eV}$, respectively. Comparison with the optical gap of 2-TDDP-SeDPP $(1.30 \mathrm{eV}, 955 \mathrm{~nm})$, reveals that transport gaps are only around $0.1 \mathrm{eV}$ larger than the optical gaps. Hence, exciton binding energies are very small in these systems. In single molecule calculations, there is no difference between Hex and TEG substituted oligomers, confirming the conclusions from GIXD experiments 


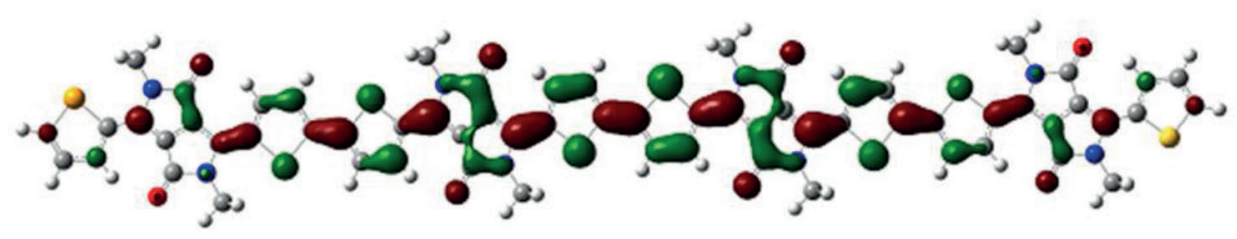

LUMO

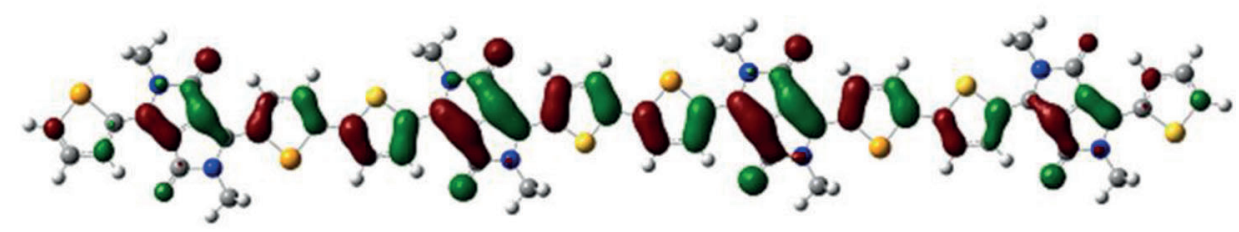

HOMO

Figure 3. HOMO and LUMO of 2-TDPP-SeDPP.

that the differences between the two polymers are due to different solid state packing.

\subsection{Electrochemical properties}

Cyclic voltammetry was employed to establish the electrochemical properties of the two selenophene-based DPP copolymers. Both polymers exhibit irreversible oxidation and reversible reduction behaviour, and corresponding cyclic voltammograms are shown in Figure 4. Two closely spaced peaks were observed in the oxidation cycle for both the polymers, whereas the reduction cycle proceeds in a single step. The appearance of dual peaks in the oxidation cycle accounts for two electron processes, corresponding to thiophene and selenophene units in the polymer backbone. This is due to the difference in the ionization potentials of sulfur and selenium. ${ }^{[2]}$ The onsets of oxidation and reduction at $0.93 \mathrm{~V}$ and $-0.79 \mathrm{~V}$ correspond to the HOMO and LUMO energy values of
$-5.43 \mathrm{eV}$ and $-3.71 \mathrm{eV}$, with respect to the internal standard ferrocene/ferrocenium for PTDPPSeDPP-Hex. Similarly, the TEG substituted polymer showed HOMO and LUMO energy levels at $-5.04 \mathrm{eV}$ and $-3.76 \mathrm{eV}$, as calculated from its onset of oxidation $(0.54 \mathrm{~V})$ and reduction $(-0.74 \mathrm{~V})$ potential, respectively. The electrochemical band gaps are $1.72 \mathrm{eV}$ and $1.28 \mathrm{eV}$ for PTDPPSeDPPHex and PTDPPSeDPP-TEG, respectively. The differences between optical and electrochemical band gaps of $0.14 \mathrm{eV}$ and $0.58 \mathrm{eV}$ are attributed to the interface barrier between the electrode and the polymer thin film, and the exciton binding energy. ${ }^{[25]}$ The summary of optical and electrochemical data is given in Table 2. The thiophene analogues of the TDPP-SeDPP copolymer showed irreversible oxidation and quasi-reversible reduction processes. ${ }^{[12]}$ The above results indicate that selenium integration into the polymer repeating units stabilizes the LUMO energy level and facilitates the electron transfer process on the surface by making it reversible. We also observed
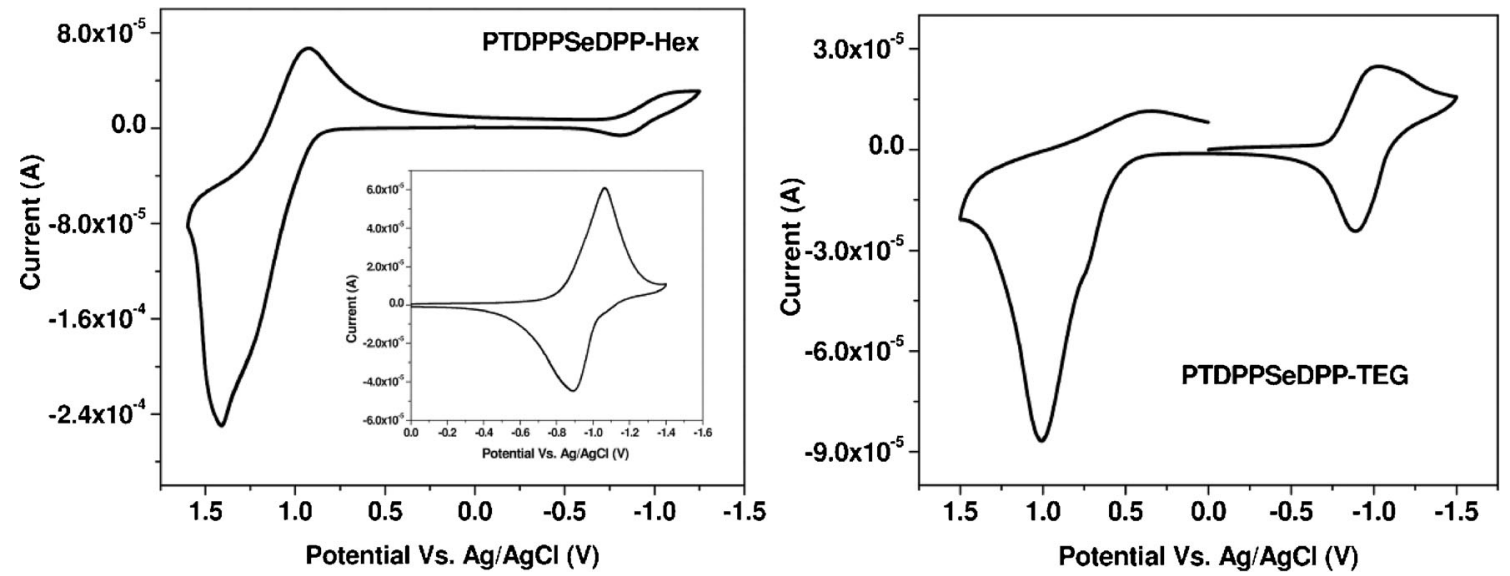

Figure 4. Cyclic voltammograms of the two copolymers, PTDPPSeDPP-Hex and PTDPPSeDPP-TEG. The reduction scan for the polymer PTDPPSeDPP-Hex is shown in the inset. 
Table 2. Summary of photophysical and electrochemical properties of the copolymers

\begin{tabular}{|c|c|c|c|c|c|c|}
\hline \multirow{2}{*}{ Polymer } & \multicolumn{3}{|c|}{ UV-vis absorption spectra } & \multicolumn{3}{|c|}{ Electrochemical properties } \\
\hline & $\frac{\overline{\text { Solution }}}{\lambda_{\max }(\mathrm{nm})}$ & $\frac{\text { Thin Film }}{\lambda_{\max }(\mathrm{nm})}$ & $E_{g}^{o p t}(e V)^{a}$ & HOMO $(\mathrm{eV})$ & LUMO (eV) & $E_{g}^{\text {elec }}(e V)$ \\
\hline PTDPPseDPP-Hex & 825 & 850 & 1.14 & -5.43 & -3.71 & 1.72 \\
\hline PTDPPSeDPP-TEG & 857 & 889 & 1.14 & -5.04 & -3.76 & 1.28 \\
\hline
\end{tabular}

${ }^{a}$ Calculated from onset of solution state absorption spectra

irreversible oxidation and degradation when we ran complete scans from positive to negative potential, whereas the reduction scan was unusually stable. To further scrutinize this, we recorded multiple cycles of the reduction process, only differing the scan speeds (SI 7). We observed that formation and stability of the anions is independent of the scan rate, implying the importance of selenium in preparing stable n-type organic semiconductors. The stability and reversibility of the reduction process was indicative of the favourable electron transport properties of selenium-containing polymers. Only during slow scans, the reduction current gradually diminished with concomitant appearance of a new peak due to the reduction of oxygen. These observations suggest that this family of polymers is a potential candidate for stable ntype polymeric semiconductors.

\subsection{Thin Film X-ray Diffraction}

Thin polymer films are characterized by X-ray diffraction studies. The X-ray diffraction patterns of two copolymer thin films are shown in Figure 5. Both polymers show intense diffraction peaks in the small angle region, which can be attributed to lamellar packing of the polymer chains in the thin film. The observed diffraction peaks at

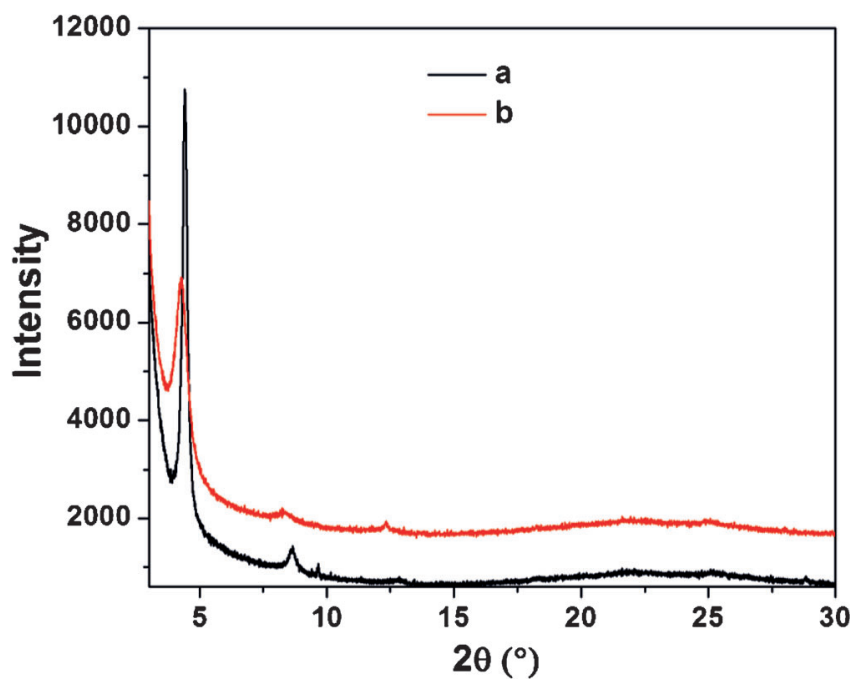

Figure 5. Thin film X-ray diffraction of (a) PTDPPSeDPP-Hex and (b) PTDPPSEDPP-TEG on silicon substrates. $4.4^{\circ}$ and $4.3^{\circ}$ were attributed to lamellar packing distances of $19.9 \AA$ and $20.4 \AA$ for PTDPPSeDPP-Hex and PTDPPSeDPP-TEG, respectively, as calculated from their peak positions. The inter-chain lamellar packing distances vary with the nature of the alkyl chain on the lactam ring. TEG substituted polymers show larger interchain packing distances than the hexyl substituted ones. Engagement in long-range ordering and intermolecular interactions via $\pi$-stacking are clearly visible from the higher-order lamellar peaks (2nd and 3rd order) in the low angle region and a broad peak at $\sim 25^{\circ}$ for both the polymers, respectively. From thin film X-ray studies, the intermolecular $\pi-\pi$ stacking distances were calculated as $3.54 \AA$ and $3.56 \AA$, corresponding to the $2 \theta$ values of $25.12^{\circ}$ and $24.99^{\circ}$ for PTDPPSeDPP-Hex and PTDPPSeDPP-TEG, respectively. As evidenced from the semicrystalline nature of the polymer thin film, the polymer chains have directional order in the solid state packing. To further understand the intricate nature of the packing of the polymer chains, GIXD studies were conducted, and the results are discussed in following section.

\subsection{GIXD Study}

GIXD experiments were performed to evaluate the molecular packing and the orientation of the polymer chain in the thin film. The polymers were drop-casted on $\mathrm{Si}$ / $\mathrm{SiO}_{2}$ substrate. Annealing of the thin films had no effect on the orientation of the polymer chains, as the diffraction patterns remained unperturbed. The GIXD patterns for the two polymers are shown in Figure 6. Upon comparison, we found that there were substantial differences between the diffraction patterns from thin films of the two polymers. The presence of higher-order out-of-plane diffraction spots with discernible intensity from lamellar packing (h00) on the $\mathrm{Q}_{\mathrm{z}}$ axis and $\pi$-stacking peak due to (010) on the $\mathrm{Q}_{\mathrm{xy}}$ axis for PTDPPSeDPP-TEG, indicates that the polymer chains are completely oriented in edgeon fashion, as shown in the figure below. Out-of-plane lamellar d-spacing of $20.1 \AA$ for the (100) plane, with a coherence length of $87.5 \AA$, was measured for the TEG substituted polymer. Similarly, in-plane d-spacing for the $\pi-$ $\pi$ stacking distance of the (010) plane was $3.57 \AA$, with a coherence length of $59.7 \AA$. On the other side, the diffraction pattern from the thin film of PTDPPSeDPP-Hex exhibits intense spots with an arc-like nature, suggesting 


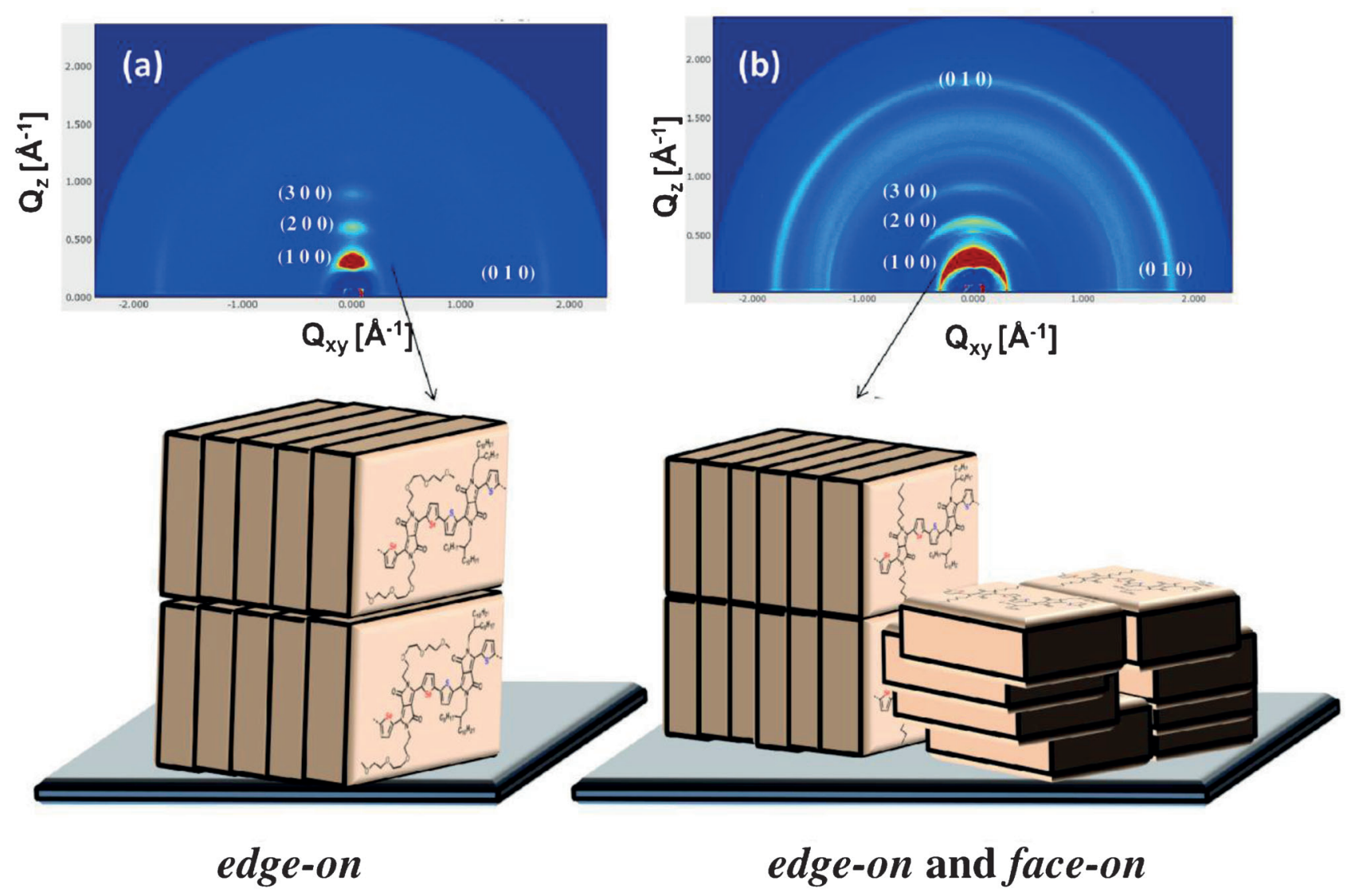

Figure 6. GIXD pattern of (a) PTDPPSeDPP-TEG and (b) PTDPPSeDPP-Hex from drop-casted thin films. Schematic orientation of the polymer chain is shown below.

the presence of misoriented crystallites in the thin film. Since the diffraction from the (010) plane appears as an arc, and is present on the $\mathrm{Q}_{\mathrm{xy}}$ as well as on the $\mathrm{Q}_{\mathrm{z}}$ axis, we can visualize the orientation of the polymer chain as a blend of edge-on and face-on orientations, as shown in Figure 6. Lamellar d-spacing of $20 \AA$ and a coherence length of $97.3 \AA$ were determined from the (100) peak of PTDPPSeDPP-Hex. A shorter $\pi-\pi$ stacking distance of $3.5 \AA$ was measured for the hexyl substituted polymer, with a coherence length of $61.1 \AA$. In polymeric semiconductors, transport of charge carriers is more efficient in the $\pi$-stacking direction. Since, in the edge-on orientation, the $\pi$-stacking direction becomes parallel to conducting channel, such packing in TEG polymers leads to more efficient charge transport than in its hexyl analogue. To confirm this hypothesis, we have measured the charge carrier mobilities of these polymers in field-effect transistor devices.

\subsection{Organic Field-Effect Transistor (OFET) Measurements}

The charge carrier mobilities of PTDPPSeDPP-Hex and PTDPPSeDPP-TEG were determined by fabricating organic field-effect transistors (OFETs). Measurements were performed on two different types of device architectures, namely: (1) bottom-gate-bottom-contact (BG-BC) and (2) top-gate-bottom-contact (TG-BC). BG-BC devices were made from $\mathrm{Si} / \mathrm{SiO}_{2}$ substrates with pre-patterned $\mathrm{Au}$ source/drain electrodes, where $\mathrm{Si}$ and $\mathrm{SiO}_{2}$ act as gate electrode and dielectric layer, respectively. The surface of $\mathrm{SiO}_{2}$ was treated with hexamethyldisilazane (HMDS) to passivate its surface and prevent the formation of charge trapping states. The polymer semiconductor layer was spun on top of the substrates to complete the transistor fabrication. On the other hand, TG-BC transistors were fabricated onto glass substrates containing pre-patterned $\mathrm{Al} / \mathrm{Au}$ source-drain electrodes. The semiconducting polymer solution was then spin cast onto the substrates, after the formation of pentafluorobenzenethiol (PFBT) self-assembled mono-layers, at room temperature, in a nitrogen atmosphere. The insulating fluoropolymer, CYTOP (Ashai Glass), was sequentially spin casted directly onto the semiconducting polymer at room temperature, followed by annealing at $100{ }^{\circ} \mathrm{C}$ for 5 minutes in nitrogen. Device fabrication was completed with the evaporation of the $\mathrm{Al}$ gate electrodes by thermal evaporation under high vacuum $\left(10^{-6} \mathrm{mbar}\right)$. 

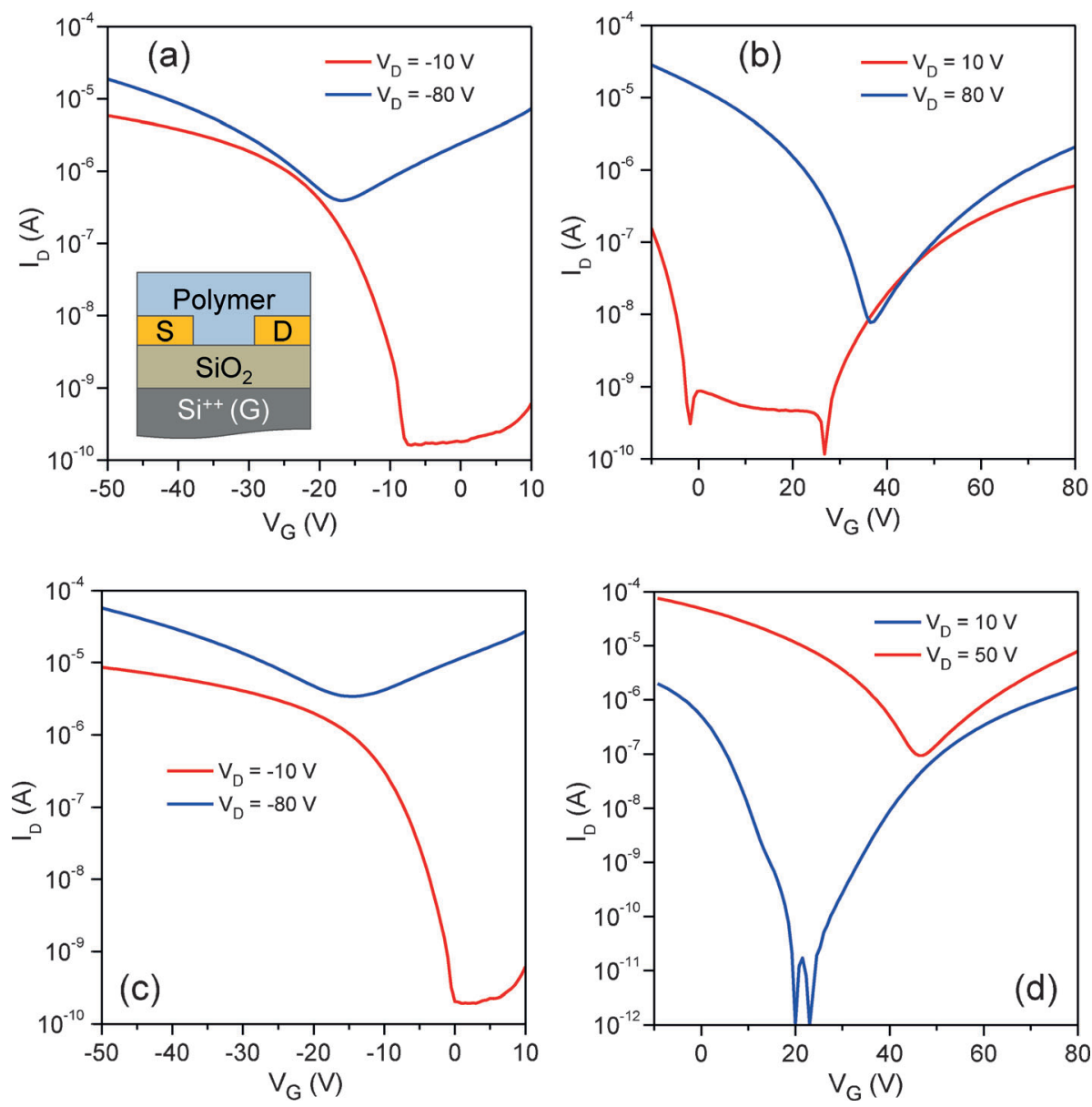

Figure 7. Transfer characteristics of PTDPPSeDPP-Hex (a), (b) and PTDPPSeDPP-TEG (c), (d) -based BG-BC transistors. (inset in 'a' shows the device architecture). (a), (c) and (b), (d) represent $\mathrm{p}$ - and n-channel operation, respectively.

The incorporation of chalcogen atoms in conjugated polymers results into ambipolar properties, ${ }^{[13,14 c, 16,22 \mathrm{a}]}$ we also observed ambipolar charge transport for both copolymers when tested in the BG-BC transistor configuration (Figure 7). For both polymers, it was found that hole mobilities were one order of magnitude higher than electron mobility values. Additionally, the TEG substituted polymer exhibited higher hole and electron mobilities, in comparison with the hexyl-substituted analogue. The hole and electron mobilities for PTDPPSeDPP-Hex were $5 \times$ $10^{-3} \mathrm{~cm}^{2} \mathrm{~V}^{-1} \mathrm{~s}^{-1}$ and $5 \times 10^{-4} \mathrm{~cm}^{2} \mathrm{~V}^{-1} \mathrm{~s}^{-1}$, but in the case of PTDPPSeDPP-TEG, the hole and electron mobilities were $1 \times 10^{-2} \mathrm{~cm}^{2} \mathrm{~V}^{-1} \mathrm{~s}^{-1}$ and $5 \times 10^{-3} \mathrm{~cm}^{2} \mathrm{~V}^{-1} \mathrm{~s}^{-1}$, respectively. The higher charge carrier mobilities measured for the TEGylated polymer devices are in accordance with the GIXD study, which reveals the presence of edge-on orientation in the thin film, while its hexyl analogue showed mixed orientation, edge-on as well as face-on, which is detrimental for long-range charge transport, as observed in previous studies. ${ }^{[26]}$ In the TG-BC device configuration, we observed electron-only transport for both polymers (SI 10). We attribute this to the different device configuration, which has been shown to result in variation in transport characteristics. ${ }^{[12,16,22 a]}$ The top-gate device architecture is known to improve the macroscopic charge transport properties of the device, due to the easier injection of charges from the source-drain electrodes into the HOMO/LUMO levels of the semiconductor, by reducing the contact resistance through an increase in the active electrode area contributing to the charge injection. The calculated electron mobilities in TG-BC transistors were found to be approximately equal $\left(\sim 1 \times 10^{-2} \mathrm{~cm}^{2} \mathrm{~V}^{-1} \mathrm{~s}^{-1}\right)$ for both polymers, exhibiting a two orders of magnitude enhancement, as compared with BG-BC devices, for PTDPPSeDPP-Hex, and one order of magnitude for PTDPPSeDPP-TEG. The on/off ratios of the transistors based on the different copolymers were similar, and in the range of $10^{3}-10^{5}$. The performance characteristics of the different polymer transistors are summarized in Table 3.

\section{Conclusions}

The present study on the selenophene-based DPP polymers has elucidated the influence of selenium in the elec- 
Table 3. Summary of the OFET device parameters for different device configuration.

\begin{tabular}{|c|c|c|c|c|c|c|c|c|c|}
\hline Polymers & $\begin{array}{l}\text { Device } \\
\text { Config. }\end{array}$ & $\mathrm{D} / \mathrm{S}$ & $\begin{array}{l}\text { Gate } \\
\text { Dielectric }\end{array}$ & $\begin{array}{l}\mu_{\mathrm{e}} \\
\left(\mathrm{cm}^{2} \mathrm{~V}^{-1} \mathrm{~s}^{-1}\right)\end{array}$ & $\begin{array}{l}\boldsymbol{\mu}_{\mathrm{h}} \\
\left(\mathrm{cm}^{2} \mathrm{~V}^{-1} \mathrm{~s}^{-1}\right)\end{array}$ & $\frac{I_{\text {on }} I_{\text {off }}}{(n)}$ & (p) & $\frac{V_{\text {Th }}}{(n)}$ & (p) \\
\hline PTDPPSeDPP-Hex & $\begin{array}{l}\text { BG-BC } \\
\text { TG-BC }\end{array}$ & $\begin{array}{l}\mathrm{Au} \\
\mathrm{Au} / \mathrm{Al}\end{array}$ & $\begin{array}{l}\mathrm{SiO}_{2} \\
\mathrm{CYTOP}\end{array}$ & $\begin{array}{l}5 \times 10^{-4} \\
1 \times 10^{-2}\end{array}$ & $\begin{array}{l}5 \times 10^{-3} \\
-\end{array}$ & $\begin{array}{l}>10^{3} \\
>10^{5}\end{array}$ & $\begin{array}{l}>10^{4} \\
-\end{array}$ & $\begin{array}{l}55 \\
45\end{array}$ & $\begin{array}{l}-20 \\
-\end{array}$ \\
\hline PTDPPSeDPP-TEG & $\begin{array}{l}\text { BG-BC } \\
\text { TG-BC }\end{array}$ & $\begin{array}{l}\mathrm{Au} \\
\mathrm{Au} / \mathrm{Al}\end{array}$ & $\begin{array}{l}\mathrm{SiO}_{2} \\
\text { CYTOP }\end{array}$ & $\begin{array}{l}5 \times 10^{-3} \\
1 \times 10^{-2}\end{array}$ & $\begin{array}{l}1 \times 10^{-2} \\
-\end{array}$ & $\begin{array}{l}>10^{5} \\
>10^{4}\end{array}$ & $\begin{array}{l}>10^{4} \\
-\end{array}$ & $\begin{array}{l}50 \\
50\end{array}$ & $\begin{array}{l}-20 \\
-\end{array}$ \\
\hline
\end{tabular}

tronic, optical, and charge transport properties. Theory and experiment agree about decrease in band gap, increase in n-type electrochemical stability, and larger EA. Although there is little electron density on the chalcogen atom in the HOMO, the selenium system has a lower ionization potential than its sulfur analogue. The conduction band is wider than the valence band, and band widths of selenium systems are slightly larger than those of the TDDP polymers. Thus, theory predicts all relevant properties for hole and electron transport to be slightly superior with selenophene than with thiophene. Nonetheless, electron mobility did not reach comparable values to those of PTDPP. It seems likely that molecular weight and film qualities need to improve to reach the full potential of this material. Work regarding optimization of thin film properties is in progress in our laboratory.

\section{Experimental Section}

\subsection{Materials and Methods}

The reagents were purchased from Sigma-Aldrich, Acros Organics, and S.D. Fine Chemicals, and they were used without further purification. Dry and distilled solvents were used for the synthesis. The ${ }^{1} \mathrm{H}$ and ${ }^{13} \mathrm{C}$ NMR spectra were recorded on a Bruker Avance NMR spectrometer at $400 \mathrm{MHz}$ frequency. $\mathrm{CDCl}_{3}$ and TMS were used as the solvent and the internal standard, respectively. Elemental analysis of the polymers was carried out using a Thermo Scientific Flash 2000 Organic Elemental Analyzer. Molecular weights $\left(M_{w}, M_{n}\right)$ were determined by gel permeation chromatography (GPC) using polystyrene as the standard, while tetrahydrofuran (THF) was used as the eluent, with a flow rate of $1 \mathrm{~mL} \mathrm{~min}^{-1}$. The optical absorption spectra of polymers in $o$-dichlorobenzene and in thin film were recorded with a Perkin-Elmer (Lambda 35) spectrometer at room temperature. The thin film for UV-visible absorption spectra was prepared by spin coating at $1500 \mathrm{rpm}$ from $o$-dichlorobenzene/chloroform. The thin film X-ray diffraction pattern was recorded on a Philips X-pert diffractometer with $\mathrm{Cu} \operatorname{Ko}(\lambda=1.5418 \AA)$ radiation. Thin film was prepared by the drop-cast method from $o$-dichlorobenzene and annealed at $140{ }^{\circ} \mathrm{C}$. GIXD measurements were performed at beamline 11-3 at the Stanford Synchrotron Radiation Lightsource (SSRL, Stanford, CA, USA). The sample to detector distance was maintained at $401.51 \mathrm{~mm}$. Lanthanum Hexaboride $\left(\mathrm{LaB}_{6}\right)$ was used to calibrate the diffraction pattern. The incident X-ray $(12.73 \mathrm{keV})$ beam was used and the critical incidence angle was evaluated at $0.12^{\circ}$ for scattering of the thin films. The scattering patterns were recorded using a MAR345 Imaging Plate and the exposure time was set to 30 seconds. Thermogravimetric analysis (TGA) was performed using a Mettler Toledo TGA SDTA 851 instrument, at a heating rate of $10^{\circ} \mathrm{C} / \mathrm{min}$ under nitrogen atmosphere. Redox properties of the polymers were evaluated by cyclic voltammetry experiments $(\mathrm{CH}$ electrochemical analyzer). $\mathrm{Ag} / \mathrm{AgCl}$ was used as the reference electrode, whereas platinum (Pt) was employed as both the working and the counter electrodes. Dry acetonitrile and tetrabutylammonium hexafluorophosphate (0.1 M) were used as the solvent and the supporting electrolyte. A ferrocene/ferrocenium $\left(\mathrm{Fc} / \mathrm{Fc}^{+}\right)$couple was used as the standard electrochemical reference. At similar experimental conditions, the oxidation peak of ferrocene appeared at $0.3 \mathrm{~V}$ vs. the $\mathrm{Ag} / \mathrm{AgCl}$ electrode. The oxidation potential for the ferrocene/ferrocenium couple corresponds to the absolute energy level of $-4.8 \mathrm{eV}$, with respect to the vacuum. The energies of HOMO and LUMO and corresponding band gaps of the polymers were calculated from their corresponding oxidation and reduction potentials. The position of HOMO and LUMO were calculated from the equation $\mathbf{1}$ and the band gap was determined from the difference between them.

$\mathrm{HOMO}=-\left(\mathrm{E}_{\mathrm{ox}}+4.5\right)>\mathrm{eV} ; \mathrm{LUMO}=-\left(\mathrm{E}_{\mathrm{red}}+4.5\right) \mathrm{eV}$

\subsection{Computational Methods}

The structures of monomers through tetramers of TDPP and SeDPP with methyl and TEG side groups, and of monomer and dimer of TDPP-SeDPP with methyl substituents were optimized. Ionization potentials and electron affinities of 4-TDDP and 2-TDPP-SDPP were calculated with the $\triangle \mathrm{SCF}$ method, in the presence of chloroform, using the polarized continuum model. ${ }^{[27]}$ Electronic spectra were calculated with TDDFT. ${ }^{[28]}$ All calculations were carried out with the B3LYP functional. In general, the 6$31 \mathrm{G}^{*}$ basis set was used; for the IPs and EAs, diffuse functions were added. The charges of ground and first excited states were obtained from a natural population anal- 
ysis (NPA). ${ }^{[29]}$ All calculations were done with Gaussian 09 Rev. A1. ${ }^{[30]}$

\subsection{Synthesis of Monomers}

The monomers 2,5-bis(2-octyldodecyl)-3,6-bis(5-(4,4,5,5tetramethyl-1,3,2-dioxaborolan-2-yl)thiophen-2-yl)pyrrolo[3,4-c]pyrrole-1,4(2H,5H)-dione (M1), 3,6-bis(5-bromoselenophen-2-yl)-2,5-dihexylpyrrolo[3,4-c]pyrrole1,4(2H,5H)-dione (M2), 3,6-bis(5-bromoselenophen-2-yl)2,5-bis(2-(2-(2-methoxyethoxy)ethoxy)ethyl)pyrrolo[3,4]pyrrole-1,4(2H,5H)-dione (M3) were synthesized according to the previously reported synthetic procedure. ${ }^{[12,16]}$

\subsection{General Procedure for the Synthesis of Polymers,} PTDPPSeDPP-Hex and PTDPPSeDPP-TEG

Both the monomers in equal molar ratio were dissolved in dry toluene, followed by purging with argon gas for 15 minutes. Then the ligand, $(o \text {-tol })_{3} \mathrm{P}$, and the catalyst, $\mathrm{Pd}_{2}(\mathrm{dba})_{3}(5 \%)$, were added to it. The mixture was evacuated and purged with argon several times. In $1 \mathrm{~mL} 2$ (M) aqueous solution of $\mathrm{K}_{3} \mathrm{PO}_{4}$ argon gas was purged for 5 minutes and then added to the above reaction mixture. The temperature was raised to $90^{\circ} \mathrm{C}$ and the reaction mixture was refluxed for 48 hours. The reaction mixture was washed with EDTA solution to remove Pd impurities. The solvent was then removed under reduced pressure, and the solid was dissolved in chloroform and precipitated in methanol. The obtained mass was washed using Soxhlet apparatus with methanol, acetone, and hexane to remove undesired low molecular weight impurities. The solid was dried under vacuum. Both the polymers, PTDPPSeDPP-Hex and PTDPPSeDPP-TEG, were obtained as a dark green solid.

\section{2,5-bis(2-octyldodecyl)-3,6-bis(5-(4,4,5,5-tetramethyl-1,3,2- dioxaborolan-2-yl)thiophen-2-yl)pyrrolo[3,4-c]pyrrole-1,4(2H,5H)- dione (M1)}

${ }^{1} \mathrm{H}$ NMR (400 MHz, $\left.\mathrm{CDCl}_{3}\right) \delta 8.91(\mathrm{~d}, J=3.9 \mathrm{~Hz}, 2 \mathrm{H})$, $7.71(\mathrm{~d}, J=3.9 \mathrm{~Hz}, 2 \mathrm{H}), 4.05(\mathrm{~d}, J=7.6 \mathrm{~Hz}, 4 \mathrm{H}), 1.89$ (s, $2 \mathrm{H}), 1.37(\mathrm{~s}, 24 \mathrm{H}), 1.31-1.16(\mathrm{~m}, 64 \mathrm{H}), 0.86(\mathrm{~m}, J=$ $6.7 \mathrm{~Hz}, 12 \mathrm{H}) \mathrm{ppm}$.

${ }^{13} \mathrm{C}$ NMR $\left(100 \mathrm{MHz}, \mathrm{CDCl}_{3}\right): \delta 161.78,140.54,137.67$, 136.13, 135.7, 108.77, 84.6, 46.3, 37.8, 31.93, 30.03, 29.65, $29.6,29.53,29.36,24.79,22.67,14.12 \mathrm{ppm}$.

\section{3,6-bis(5-bromoselenophen-2-yl)-2,5-dihexylpyrrolo[3,4-c]pyrrole- 1,4(2H,5H)-dione (M2)}

${ }^{1} \mathrm{H}$ NMR (400 MHz, $\left.\mathrm{CDCl}_{3}\right) \delta 8.45(\mathrm{~d}, J=4.3 \mathrm{~Hz}, 2 \mathrm{H})$, $7.42(\mathrm{~d}, J=4.3,4.0 \mathrm{~Hz}, 2 \mathrm{H}), 3.92(\mathrm{t}, 4 \mathrm{H}), 1.72(\mathrm{~m}, 4 \mathrm{H})$, $1.42-1.39(\mathrm{~m}, 4 \mathrm{H}), 1.33-1.26(\mathrm{~m}, 8 \mathrm{H}), 0.89(\mathrm{t}, J=7.0 \mathrm{~Hz}$, 6H) ppm.
${ }^{13} \mathrm{C}$ NMR $\left(100 \mathrm{MHz}, \mathrm{CDCl}_{3}\right): \delta 161.25,140.59,135.97$, 135.67, 134.51, 124.12, 42.31, 31.39, 29.97, 29.72, 26.60, 22.54, $13.39 \mathrm{ppm}$.

\section{3,6-bis(5-bromoselenophen-2-yl)-2,5-bis(2-(2-(2-methoxy- ethoxy)ethoxy)ethyl)pyrrolo[3,4-c]pyrrole-1,4(2H,5H)-dione (M3)}

${ }^{1} \mathrm{H}$ NMR (400 MHz, $\left.\mathrm{CDCl}_{3}\right) \delta 8.40(\mathrm{~d}, J=4.4 \mathrm{~Hz}, 2 \mathrm{H})$, $7.40(\mathrm{~d}, J=4.4 \mathrm{~Hz}, 2 \mathrm{H}), 4.12(\mathrm{t}, J=5.7 \mathrm{~Hz}, 4 \mathrm{H}), 3.80(\mathrm{t}$, $J=5.7 \mathrm{~Hz}, 4 \mathrm{H}), 3.64(\mathrm{dd}, J=5.8,3.0 \mathrm{~Hz}, 4 \mathrm{H}), 3.61-3.55$ $(\mathrm{m}, \quad 12 \mathrm{H}), \quad 3.50 \quad(\mathrm{dd}, \quad J=6.0, \quad 3.3 \mathrm{~Hz}, 4 \mathrm{H}), 3.35 \quad(\mathrm{~s}$, $6 \mathrm{H}) \mathrm{ppm} .{ }^{13} \mathrm{C}$ NMR $\left(100 \mathrm{MHz}, \mathrm{CDCl}_{3}\right): \delta 161.65,141.55$, $135.95,135.79,134.18,129.40,124.62,71.96,70.83$, 70.57,70.39, 69.70, 69.04, 66.51, 59.04, 42.67 ppm.

\section{PTDPPSeDPP-Hex}

${ }^{1} \mathrm{H} \mathrm{NMR}\left(\mathrm{CDCl}_{3}, 400 \mathrm{MHz}\right): \delta$ 9.2-8.5 (br, 4H), 7.5-7.2 (br, 4H), 4.1-3.9 (br, 8H), 2.1-0.5 (m, 100H) ppm. Elemental Analysis: Calc. (\%): $\left(\mathrm{C}_{80} \mathrm{H}_{118} \mathrm{~N}_{4} \mathrm{O}_{4} \mathrm{~S}_{2} \mathrm{Se}_{2}\right)$ : C, 67.58; H, 8.36; N, 3.94; S, 4.51 Found (\%): C, 64.85; H, 7.84; N, $3.87 ; \mathrm{S}, 3.65$.

\section{PTDPPSEDPP-TEC}

${ }^{1} \mathrm{H}$ NMR(CDCl $\left.3,400 \mathrm{MHz}\right): \delta 9.4-8.5$ (br, 4H), 7.4-6.9 (br, 4H), 4.6-3.2 (br, 34H), 2.1-0.5 (m, 78H) ppm. Elemental Analysis: Calc. (\%): $\left(\mathrm{C}_{82} \mathrm{H}_{122} \mathrm{~N}_{4} \mathrm{O}_{10} \mathrm{~S}_{2} \mathrm{Se}_{2}\right)$ : C, 63.71; H, 7.95; N, 3.62; S, 4.15 Found (\%): C, 61.18; H, 7.49; N, $3.36 ; \mathrm{S}, 3.28$.

\section{Acknowledgments}

The authors are greatly thankful to Ned Burnett and Dr. Alejandro Briseno for the analysis of the GIXD data. The authors thank the Department of Science and Technology (DST), New Delhi for providing the research grant. Joydeep Dhar gratefully acknowledges the Council of Scientific and Industrial Research (CSIR) for his senior research fellowship (SRF). Authors acknowledge NMR Research Center, IISc, Bangalore for their assistance in recording the NMR spectra.

\section{References}

[1] Y. J. Cheng, S. H. Yang, C. S. Hsu, Chem. Rev. 2009, 109, $5868-5923$.

[2] a) E. E. Havinga, W. Tenhoeve, H. Wynberg, Synth. Met. 1993, 55, 299-306; b) R. S. Kularatne, H. D. Magurudeniya, P. Sista, M. C. Biewer, M. C. Stefan, J. Polym. Sci. Part A: Polym. Chem. 2013, 51, 743-768; c) T. Wang, N. W. Scarratt, H. A. Yi, A. D. F. Dunbar, A. J. Pearson, D. C. Watters, T. S. Glen, A. C. Brook, J. Kingsley, A. R. Buckley, M. W. A. Skoda, A. M. Donald, R. A. L. Jones, A. Iraqi, D. G. Lidzey, Adv. Energy Mater. 2013, 3, 505-512. 
[3] a) Y. F. Li, Acc. Chem. Res. 2012, 45, 723-733; b) P. M. Beaujuge, C. M. Amb, J. R. Reynolds, Acc. Chem. Res. 2010, 43, 1396-1407.

[4] J. B. You, L. T. Dou, K. Yoshimura, T. Kato, K. Ohya, T. Moriarty, K. Emery, C. C. Chen, J. Gao, G. Li, Y. Yang, Nat. Commun. 2013, 4.

[5] a) U. Salzner, M. E. Kose, J. Phys. Chem. B 2002, 106, 9221-9226; b) U. Salzner, O. Karalti, S. Durdagi, J. Mol. Model. 2006, 12, 687-701.

[6] H. Huang, P. G. Pickup, Chem. Mater. 1998, 10, 2212-2216.

[7] H. Usta, C. Risko, Z. M. Wang, H. Huang, M. K. Deliomeroglu, A. Zhukhovitskiy, A. Facchetti, T. J. Marks, J. Am. Chem. Soc. 2009, 131, 5586-5608.

[8] a) C. L. Wang, H. L. Dong, W. P. Hu, Y. Q. Liu, D. B. Zhu, Chem. Rev. 2012, 112, 2208-2267; b) H. Usta, A. Facchetti, T. J. Marks, Acc. Chem. Res. 2011, 44, 501-510.

[9] a) S. Y. Qu, H. Tian, Chem. Commun. 2012, 48, 3039-3051; b) C. B. Nielsen, M. Turbiez, I. McCulloch, Adv. Mater. 2013, 25, 1859-1880; c) Y. N. Li, P. Sonar, L. Murphy, W. Hong, Energy Environ. Sci. 2013, 6, 1684-1710.

[10] a) H. N. Tsao, D. M. Cho, I. Park, M. R. Hansen, A. Mavrinskiy, D. Y. Yoon, R. Graf, W. Pisula, H. W. Spiess, K. Mullen, J. Am. Chem. Soc. 2011, 133, 2605-2612; b) H. J. Chen, Y. L. Guo, G. Yu, Y. Zhao, J. Zhang, D. Gao, H. T. Liu, Y. Q. Liu, Adv. Mater. 2012, 24, 4618-4622.

[11] I. Kang, H. J. Yun, D. S. Chung, S. K. Kwon, Y. H. Kim, J. Am. Chem. Soc. 2013, 135, 14896-14899.

[12] C. Kanimozhi, N. Yaacobi-Gross, K. W. Chou, A. Amassian, T. D. Anthopoulos, S. Patil, J. Am. Chem. Soc. 2012, 134, $16532-16535$.

[13] a) J. Lee, A. R. Han, J. Kim, Y. Kim, J. H. Oh, C. Yang, J. Am. Chem. Soc. 2012, 134, 20713-20721; b) J. Lee, A. R. Han, H. Yu, T. J. Shin, C. Yang, J. H. Oh, J. Am. Chem. Soc. 2013, 135, 9540-9547.

[14] a) A. J. Kronemeijer, E. Gili, M. Shahid, J. Rivnay, A. Salleo, M. Heeney, H. Sirringhaus, Adv. Mater. 2012, 24, 1558-1565; b) L. Burgi, M. Turbiez, R. Pfeiffer, F. Bienewald, H. J. Kirner, C. Winnewisser, Adv. Mater. 2008, 20, 2217-2224; c) Z. Y. Chen, M. J. Lee, R. S. Ashraf, Y. Gu, S. Albert-Seifried, M. M. Nielsen, B. Schroeder, T. D. Anthopoulos, M. Heeney, I. McCulloch, H. Sirringhaus, $A d v$. Mater. 2012, 24, 647-652.

[15] C. Kanimozhi, N. Yaacobi-Gross, E. K. Burnett, A. L. Briseno, T. D. Anthopoulos, U. Salzner, S. Patil, Phys. Chem. Chem. Phys. (submitted) 2014.

[16] M. Shahid, T. McCarthy-Ward, J. Labram, S. Rossbauer, E. B. Domingo, S. E. Watkins, N. Stingelin, T. D. Anthopoulos, M. Heeney, Chem. Sci. 2012, 3, 181-185.

[17] a) M. Heeney, W. Zhang, D. J. Crouch, M. L. Chabinyc, S. Gordeyev, R. Hamilton, S. J. Higgins, I. McCulloch, P. J. Skabara, D. Sparrowe, S. Tierney, Chem. Commun. 2007, 5061-5063; b) A. A. B. Alghamdi, D. C. Watters, H. N. Yi, S. Al-Faifi, M. S. Almeataq, D. Coles, J. Kingsley, D. G. Lidzey, A. Iraqi, J. Mater. Chem. A 2013, 1, 5165-5171; c) K. Oyaizu, T. Iwasaki, Y. Tsukahara, E. Tsuchida, Macromolecules 2004, 37, 1257-1270.

[18] a) G. L. Gibson, T. M. McCormick, D. S. Seferos, J. Am. Chem. Soc. 2011, 134, 539-547; b) I. Kang, T. K. An, J. A. Hong, H. J. Yun, R. Kim, D. S. Chung, C. E. Park, Y. H. Kim, S. K. Kwon, Adv. Mater. 2013, 25, 524-528.

[19] U. Salzner, J. B. Lagowski, P. G. Pickup, R. A. Poirier, Synth. Met. 1998, 96, 177-189.
[20] a) Z. Y. Chen, H. Lemke, S. Albert-Seifried, M. Caironi, M. M. Nielsen, M. Heeney, W. M. Zhang, I. McCulloch, H. Sirringhaus, Adv. Mater. 2010, 22, 2371-2375; b) J. S. Ha, K. H. Kim, D. H. Choi, J. Am. Chem. Soc. 2011, 133, 10364-10367.

[21] a) S. S. Zade, N. Zamoshchik, M. Bendikov, Chem. Eur. J. 2009, 15, 8613-8624; b) A. Patra, M. Bendikov, J. Mater. Chem. 2010, 20, 422-433.

[22] a) H. W. Lin, W. Y. Lee, W. C. Chen, J. Mater. Chem. 2012, 22, 2120-2128; b) M. Shahid, R. S. Ashraf, Z. G. Huang, A. J. Kronemeijer, T. McCarthy-Ward, I. McCulloch, J. R. Durrant, H. Sirringhaus, M. Heeney, J. Mater. Chem. 2012, 22, 12817-12823.

[23] a) A. B. Tamayo, B. Walker, T. Q. Nguyen, J. Phys. Chem. C 2008, 112, 11545-11551; b) G. Lohaus, Chem. Ber. 1967, $100,2719-2729$.

[24] J. Dhar, N. Venkatramaiah, A. Anitha, S. Patil, J. Mater. Chem. C 2014, 2, 3457-3466.

[25] a) Z. K. Chen, W. Huang, L. H. Wang, E. T. Kang, B. J. Chen, C. S. Lee, S. T. Lee, Macromolecules 2000, 33, 90159025; b) H. Y. Chen, S. C. Yeh, C. T. Chen, J. Mater. Chem. 2012, 22, 21549-21559; c) I. G. Hill, A. Kahn, Z. G. Soos, R. A. Pascal, Chem. Phys. Lett. 2000, 327, 181-188.

[26] a) M. S. Chen, O. P. Lee, J. R. Niskala, A. T. Yiu, C. J. Tassone, K. Schmidt, P. M. Beaujuge, S. S. Onishi, M. F. Toney, A. Zettl, J. M. J. Frechet, J. Am. Chem. Soc. 2013, 135, 19229-19236; b) X. R. Zhang, L. J. Richter, D. M. DeLongchamp, R. J. Kline, M. R. Hammond, I. McCulloch, M. Heeney, R. S. Ashraf, J. N. Smith, T. D. Anthopoulos, B. Schroeder, Y. H. Geerts, D. A. Fischer, M. F. Toney, J. Am. Chem. Soc. 2011, 133, 15073-15084.

[27] a) M. Cossi, V. Barone, R. Cammi, J. Tomasi, Chem. Phys. Lett. 1996, 255, 327-335; b) V. Barone, M. Cossi, J. Tomasi, J. Chem. Phys. 1997, 107, 3210-3221; c) E. Cances, B. Mennucci, J. Tomasi, J. Chem. Phys. 1997, 107, 3032-3041.

[28] a) R. E. Stratmann, G. E. Scuseria, M. J. Frisch, J. Chem. Phys. 1998, 109, 8218-8224; b) M. E. Casida, C. Jamorski, K. C. Casida, D. R. Salahub, J. Chem. Phys. 1998, 108, 4439-4449; c) R. Bauernschmitt, R. Ahlrichs, Chem. Phys. Lett. 1996, 256, 454-464.

[29] A. E. Reed, L. A. Curtiss, F. Weinhold, Chem. Rev. 1988, $88,899-926$.

[30] M. J. Frisch, H. B. Schlegel, G. E. Scuseria, M. A. Robb, J. R. Cheeseman, G. Scalmani, V. Barone, B. Mennucci, G. A. Petersson, H. Nakatsuji, M. Caricato, H. P. Hratchian, A. F. Izmaylov, J. Bloino, G. Zheng, J. L. Sonneberg, M. Hada, M. Ehara, K. Toyota, R. Fukuda, J. Hasegawa, M. Ishida, T. Nakajima, Y. Honda, O. Kitao, H. Nakai, T. Vreven, J. A. Montgomery, Jr., J. E. Peralta, F. Ogliaro, M. Bearpark, J. J. Heyd, E. Brothers, K. N. Kudin, V. N. Staroverov, R. Kobayashi, J. Normand, K. Raghavachari, A. Rendell, J. C. Burant, S. S. Iyengar, J. Tomasi, M. Cossi, N. Rega, J. M. Millam, M. Klene, J. E. Knox, J. B. Cross, V. Bakken, C. Adamo, J. Jaramillo, R. Gomperts, R. E. Stratmann, O. Yazyev, A. J. Austin, R. Cammi, C. Pomelli, J. W. Ochterski, R. L. Martin, K. Morokuma, V. G. Zakrzewski, G. A. Voth, P. Salvador, J. J. Dannenberg, S. Dapprich, A. D. Daniels, O. Farkas, J. B. Foresman, J. V. Ortiz, J. Cioslowski and D. J. Fox, Gaussian, Inc., Wallingford, CT, 2009.

Received: February 12, 2014 Accepted: March 28, 2014 